\title{
The nursing career structure as seen by a hospital doctor
}

\author{
F B GIBBERD
}

Doctors are fortunate. However high they rise in their career it is possible for them to continue to practise medicine. I remember working for a president of the Royal College of Physicians who became a member of the House of Lords, and being impressed that he still did ward rounds and had National Health Service patients under his care. Nurses are less fortunate because they cannot go on nursing if they rise above the level of a ward sister. Above that level they may be called nurses but they are in fact administrators. Nursing officers (and senior, district, and regional nursing officers) should be more correctly named nursing administrators. Of course, there are doctors who administrate and do not admit it in their title: perhaps regional medical officers and the chief medical officers should be called regional medical administrators and chief medical administrators. Nevertheless, there are few of these doctors compared with the number of clinical consultants.

There is no way for a nurse who is promoted to remain a practising nurse. The number of nurses in administration is too high: in some places there are fewer than five ward sisters to every full time nursing administrator above them. The epitome of hospital nursing is the ward sister, and her status needs to be improved. Similar ideas could be advanced about nursing education and nursing tutors. The most senior doctors are fortunate in being able to continue teaching medical students and practising medicine until they retire, but nursing tutors have removed themselves from active nursing.

By using the term nursing officer an army rank is suggested, but the administration of nursing is less well organised than that of the army. In a fighting unit of the army those in administration are junior not only to their commander but also to the junior commanders whom they manage. Does the nursing administration really require so many senior nurses to supervise so few ward sisters ? Perhaps a small number of senior administrators helped by nurses junior to a ward sister would be a better scheme. Hospital administrators are important and usually good at their work, but they are not doctors nor are they nurses. To give nursing its rightful place in hospitals it must be shown that senior nurses are concerned in clinical work. If all clinical nursing can be delegated to juniors is nursing important?

\section{Rationalising the administrators}

The figure shows a possible career structure. The senior nursing administrator would delegate jobs to the junior nursing administrator so that the total number of senior administrators would be small and the senior ward sister would be a more experienced nurse. A senior nursing administrator would be necessary to make major policy decisions, but routine administration would be done by junior nursing administrators working closely with the ward sisters and guided by the senior ward sisters. It would be impossible to be promoted to a senior nursing administrator without having been a junior nursing administrator and a junior and senior ward sister. Similarly, it would be impossible to become a senior ward sister without

Westminster Hospital, London SW1P 2AP

F B GIBBERD, MD, FRCP, physician

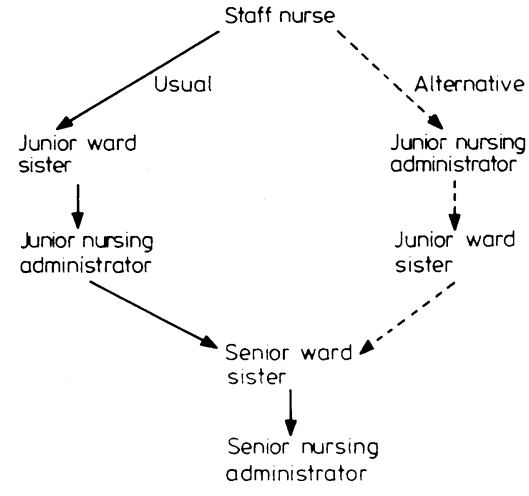

Proposed career structure for nursing.

having spent a period of time in administration. The junior ward sister and junior nursing administrator would be of equal status. The duties in the ward for a senior and junior ward sister would be similar, but having two grades would ensure that among the ward sisters there would be some with greater experience. About one in five of the sisters would be a senior ward sister. In an average sized district hospital this would probably mean one senior ward sister in each division-for example, medicine or surgery.

The salary scale and career structure for hospital doctors are organised with the hope that those doctors will all become consultants. The junior doctor receives a salary relatively close to the consultant's. Table I shows the relative salaries for doctors since April 1982. For nurses the scale is different, and

\begin{tabular}{lc}
$\begin{array}{l}\text { TABLE I-Relative } \\
\text { appointment }\end{array}$ & salaries for doctors on first \\
\multicolumn{1}{c}{ Grade } & $\begin{array}{c}\text { Relative salary } \\
\text { since April } \\
1982\end{array}$ \\
\hline Student & 0 (means tested grant) \\
Preregistration houseman & $1 \cdot 2$ \\
Senior house officer & $1 \cdot 2$ \\
Registrar & $1 \cdot 4$ \\
Senior registrar & $1 \cdot 6$ \\
Consultant & $2 \cdot 8$ \\
\hline
\end{tabular}

few nurses can expect to rise to the top grade. Table II shows relative salaries for nurses when last agreed in March 1982. Incredibly, the most senior nurse engaged in clinical work, the ward sister, earned only $£ 5628$ in $1981-2$ while the regional nursing officer earned $£ 17123$. Could it be that this disparity is because no nurse wants to be a senior administrator and has to be encouraged to take the job ? I suspect that the real reason is that those who drew up the wage structure did not consider nursing patients to be important. Table III shows a possible relative salary scale.

Junior doctors are fortunate. Twenty five years ago their pay was low and their hours of work excessively long. Their pay and hours of work have improved in a way that ward sisters have 


\section{Medical academic staff}

\section{Private practice for personal gain}

Whole time Health Service consultants are able to earn up to $10 \%$ above their NHS salary from private practice. Furthermore, the total remuneration of NHS consultants includes an element of income from fee payments for particular items of service, such as domiciliary visits. It has been the policy of the clinical academic staff salaries committee, which negotiates on behalf of clinical academic staff with the Committee of Vice chancellors and Principals and the University Grants Committee, that an additional salary element should be introduced for clinical academic staff to take account of this shortfall to restore comparability. The financial cuts imposed on universities have deferred this prospect, and in 1981 the conference of medical academic representatives (COMAR) resolved:

"That in view of the evidence that $(i)$ the financial discrepancy between honorary consultant staff and NHS consultants is detrimental to the quality of applicants for academic consultant posts, and (ii) the Committee of Vice Chancellors and Principals has so far failed to agree to an enhanced rolled up salary for clinical academic staff, honorary consultant staff should be granted the same right to private practice as their whole time NHS colleagues."

At the meeting on 17 February of the clinical academic staff salaries committee the university side reported that:

"The vice chancellors committee considered the question of private practice for personal gain by senior clinical academic staff in the light of the various relevant issues. After a careful examination of these issues the committee took the view that it would wish to maintain its present stance of opposition to private practice for personal gain while recognising that universities would necessarily make their individual decisions on this as on other matters of terms and conditions of service in the light of their particular circumstances."

\section{Local negotiations urged}

The chairman of the clinical subcommittee of the BMA's Medical Academic Staff Committee has told the clinical representatives of the conference of medical academic representa- tives of this decision and in his letter goes on to $\underline{\underline{T}}$ say:

"As you know, the staff side has taken the view that private practice is a salary related $\frac{\varrho}{c}$ matter. However, the university side has interpreted it as being one of terms and conditions of service and is unwilling to $\vec{J}$ continue negotiations. The Medical Academic D Staff Committee is seeking a way round the impasse, but in the meantime is advising $\stackrel{0}{\varrho}$ clinical COMAR representatives to make formal requests to the individual vice chancellors/deans of medical schools/institutes $\stackrel{0}{\rightarrow}$ that clinical academic staff be given the right to carry out private practice for personal gain on the same terms as those available to NHS whole time consultant staff.

"The Medical Academic Staff Committee is aware that Oxford University has granted क this right to clinical academic staff, another $\overrightarrow{0}$ university is recommending similar arrangements, and two others are giving the matter $\vec{\omega}$ urgent and serious consideration. Despite the rejection of the principle of private practice $\frac{3}{3}$ for personal gain by the national committee of vice chancellors and principals, it would ap- $\infty$ pear that individual vice chancellors are acting independently to give clinical academic $\mathcal{E}$ staff this right. The Medical Academic Staff $\infty$ Committee suggests that you should seek to 0 take advantage of this and begin local nego- $\bar{\omega}$ tiations with your vice chancellor/the dean of $\frac{\mathrm{O}}{\mathrm{s}}$ your medical school/institute." been unable to achieve. A ward sister used to be paid more than a preregistration house officer. His or her salary has now fallen relative to the junior doctor's (table IV). If the extra pay that most junior doctors receive from their units of medical time is included the ward sister's salary compares even less favourably.

\begin{tabular}{lc}
$\begin{array}{l}\text { TABLE II-Relative salaries } \\
\text { first appointment }\end{array}$ \\
\hline \multicolumn{1}{c}{ Grade } & $\begin{array}{c}\text { Relative salary } \\
\text { at March } \\
1982\end{array}$ \\
\hline Student nurse & 1 \\
Staff nurse & $1 \cdot 3$ \\
Ward sister & $1 \cdot 7$ \\
Nursing officer & $1 \cdot 9$ \\
Senior nursing officer & $2 \cdot 1$ \\
District nursing officer & $4 \cdot 6$ \\
Regional nursing officer & $5 \cdot 2$ \\
\hline
\end{tabular}

TABLE III-Suggested relative salaries for nurses

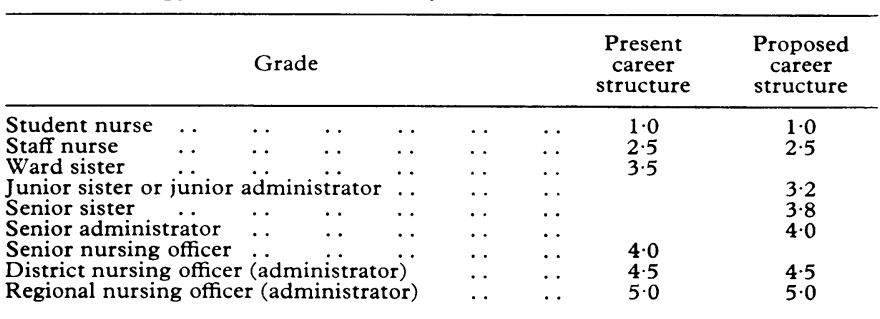

TABLE IV-Comparison of salaries of ward sisters and junior doctors

\begin{tabular}{lll}
\hline & 1957 & 1982 \\
\hline Preregistration house officer & $£ 425$ & $£ 6500+$ units of medical time \\
Ward sister & $£ 513$ & $£ 5628$ \\
Senior house officer & $£ 852$ & $£ 7700+$ units of medical time \\
\hline
\end{tabular}

During the past 25 years, however, the responsibility and skill 0 required of a ward sister have not declined.

It is surprising how little more a staff nurse is paid than a student nurse (table II), on whom a large amount of money is being spent in training. If the NHS wants to retain registered $\frac{0}{D}$ nurses it should pay them substantially more than untrained ones. An unqualified nurse should expect to receive a small salary more akin to a student grant than a career salary in the expectation that when fully qualified she will be able to earn a good salary and be encouraged to devote her career to nursing. A suggested relative salary scale is shown in table III.

I make no apologies for any mistakes or for appearing naive, but if people disagree with me I hope that this article will stimulate them to suggest a better way to help the nursing profession.

\section{Conclusions}

- Ward sisters should be given a higher position in the nursing hierarchy.

- Nurses who administer and do no nursing should be called nursing administrators.

- A new structure is suggested. After doing a period of nursing $\stackrel{O}{\leftarrow}$ administration a nurse should become a senior ward sister $\mathscr{\Phi}$ before becoming a senior administrator. There should be fewer nursing administrators senior to a ward sister. Nurses junior to a ward sister or of ward sister status should do a period of administration.

Whatever the future career structure of the nursing profession the salary of the ward sister should be higher than at present relative to the salaries of student nurses, senior nursing administrators, and medical staff.

(Accepted 3 February 1983)

Published by the Proprietors, THE BRITISH MEDICAL ASSOCIATION, Tavistock Square, London WC1H 9JR, and printed in Great Britain by George Pulman and Sons Limited of London and Bletchley, Typesetting by Bedford Typesetters Limited, Bedford. 